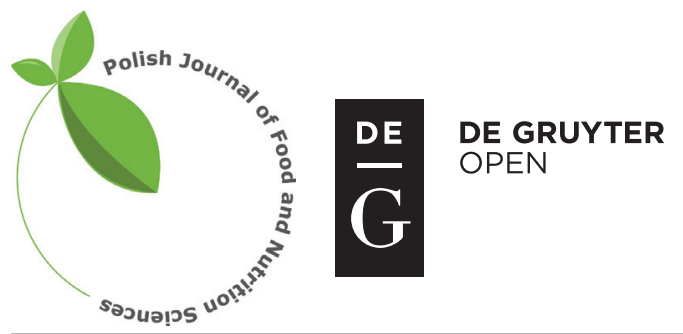

Pol. J. Food Nutr. Sci., 2017, Vol. 67, No. 2, pp. 117-122

DOI: $10.1515 /$ pjfns-2016-0011 http://journal.pan.olsztyn.pl

Original research article

Section: Food Technology

\title{
Effect of High Pressure and Sub-Zero Temperature on Total Antioxidant Capacity and the Content of Vitamin C, Fatty Acids and Secondary Products of Lipid Oxidation in Human Milk
}

\author{
Dorota Martysiak-Żurowska ${ }^{1 *}$, Matgorzata Puta ${ }^{1}$, Natalia Barczak ${ }^{1}$, Joanna Dqbrowska ${ }^{1}$, \\ Edyta Malinowska-Pańczyk ${ }^{1}$, Bogumita Kietbratowska ${ }^{2}$, Ilona Kotodziejska ${ }^{1}$
}

\author{
'Department of Food Chemistry, Technology and Biotechnology, Chemical Faculty, Gdansk University of Technology, \\ G. Narutowicza Street 11/12, 80-233 Gdansk, Poland \\ ${ }^{2}$ Department of Obstetrics, Medical University of Gdansk, Kliniczna Street 1a, 80- 402 Gdansk, Poland
}

Key words: human milk, high pressure, total antioxidant capacity, fatty acids, vitamin C

The objective of this study was to compare of the effects of high pressure of $193 \mathrm{MPa}$ at $-20^{\circ} \mathrm{C}$ and Low Temperature Long Time pasteurization (LTLT or holder pasteurization, $62.5^{\circ} \mathrm{C}, 30 \mathrm{~min}$ ) on the content and composition of fatty acids (FAs), concentrations of secondary products of lipid oxidation (TBARS), the total antioxidant capacity (TAC), total vitamin C and ascorbic acid (AsA) content in human milk. It was shown that no significant changes in the content and composition of FAs and TBARS levels were noted in both pressurized and LTLT pasteurized milk samples. The results obtained indicate that the antioxidant properties in pressurized human milk were also not affected. In the case of the pasteurized samples only slight (approx. 6\%) and statistically insignificant decrease was observed in the Trolox equivalent antioxidant capacity (TEAC) values. Pasteurization significantly reduced the content of total vitamin C and AsA, by $35 \%$ and 24\%, respectively. A minor and statistically insignificant (approx. 6\%) decrease in vitamin $\mathrm{C}$ levels was observed in milk treated with high pressure. However, a significant decrease (by more than $11 \%$ ) occurred in these conditions in AsA concentrations. The influence of high pressure treatment on AsA levels and the lack of significant changes in TEAC values point to the relative stability of the remaining antioxidant components in human milk. Further research is needed to determine the effects of high pressure of approximately $200 \mathrm{MPa}$ and sub-zero temperatures on, mainly thermolabile, components of human milk, which are degraded by LTLT pasteurization.

\section{INTRODUCTION}

Breastfeeding is the best way to feed a newborn and a small child. Human milk is characterized by an optimal quantitative and qualitative balance of nutrients which are essential for healthy growth at every stage of development. Newborns, in particular premature infants, should be fed human milk from the corresponding lactation phase. If, for some reason, a child cannot be fed orally or with the mother's milk, nourishment that is most appropriate in a given stage of development can be obtained from a human milk bank (HMB). In HMB, milk is treated by Low Temperature Long Time (LTLT) pasteurization at $62.5^{\circ} \mathrm{C}$ for $30 \mathrm{~min}$, which is also known as holder pasteurization. Pasteurization minimizes the risk of transfer of pathogenic agents such as cytomegalovirus, hepatitis B, HIV and microbial infections which are particularly dangerous for premature infants. However, LTLT contributes to significant degradation of thermolabile bioactive components and decreases the nutritional value of human milk [Van Gysel et al., 2012; Tully et al., 2001].

\footnotetext{
* Corresponding Author: Tel.: +48 5834713 06; fax: +48 583472694 . E-mail address: dorota.martysiak-zurowska@pg.gda.pl (D. MartysiakŻurowska)
}

Lipids, including polyunsaturated fatty acids (PUFAs), are vital components of human milk. In addition to the precursors of n-6 and n-3 long-chain PUFAs (LC-PUFAs), namely linoleic acid (LA) C18:2n-6 and $\alpha$-linolenic acid (ALA) C18:3n-3, human milk also contains the metabolites of both fatty acid (FA) families. The most nutritionally important FAs in human milk are: arachidonic acid (AA), eicosapentaenoic acid (EPA), docosapentaenoic acid (DPA) and docosahexaenoic acid (DHA). The demand for LC-PUFAs is determined by their role in the development of the nervous system and the retina [Stolarczyk \& Socha, 2002; Januszewicz et al., 1999]. In infants, the enzymatic system is not yet fully developed, and is incapable of producing sufficient quantities of LC-PUFAs which have to be supplied in the diet [Kent et al., 2006; Innis et al., 1999; Emmett et al., 1997].

Human milk lipids are characterized by high PUFA levels, which makes them susceptible to oxidation. The degree of lipid oxidation can be determined based on the concentrations of secondary oxidation products [Esterbauer et al., 1991; Turoli et al., 2004]. The human body needs antioxidant substances to maintain a state of homeostasis. Newborns, in particular premature infants, are exposed to powerful oxidative stress. Antioxidants present in the mother's milk eliminate excessive quantities of reactive oxygen species (ROS) from cells in a baby's body [Friel et al., 2004; Canfield et al., 2003]. 
One of such antioxidants is vitamin $\mathrm{C}$ which is present in human milk in higher concentrations than other vitamins. Vitamin $\mathrm{C}$ is highly sensitive to external factors, and is one of the key indicators of changes in food products that are induced by processing [Moltó-Puigmartí et al., 2011; Siegel, 1993].

In view of the above, the preservation methods deployed by HMB should induce minimal changes in the nutritional composition of human milk. Continued efforts are made to develop new processing techniques that guarantee microbiological safety while preserving the nutritional and biological value of milk. One of the proposed solutions involves the use of high pressure to limit nutrient loss and preserve the product's sensory properties [Tewari et al., 1999] and selected biologically active components, such as lysozyme and peroxidase [Viazis et al., 2007; Mazri et al., 2012]. The bactericidal effects of high pressure are enhanced at below-zero temperatures [Hayakawa et al., 1998].

The objective of this study was to determine the effect of high pressure $(193 \mathrm{MPa})$ applied at a temperature of $-20^{\circ} \mathrm{C}$ on the content and composition of FAs, the degree of FA oxidation based on the concentrations of secondary products of lipid oxidation, the antioxidant capacity and vitamin $\mathrm{C}$ content of human milk, and to compare the above results with the outcomes of LTLT pasteurization.

All research procedures were approved by the Local Ethics Committee of the Medical University of Gdansk. The subjects gave their informed consent before the start of any procedure.

\section{MATERIALS AND METHODS}

\section{Material}

The experimental material comprised mature milk from seven healthy mothers, residents of Gdańsk, who gave birth to term babies at the Maternity Ward of the Clinical Hospital in Gdańsk. No complications were reported in any of the subjects in the perinatal period. All infants were born in good condition and with normal birth weight (3100-3800 g).

\section{Milk collection}

Milk was collected by the mothers with the use of an electric breast pump (Symphony, Medela) in accordance with general hygiene standards. It was collected within $24 \mathrm{~h}$ and refrigerated at $4^{\circ} \mathrm{C}$. Milk samples were pooled and divided into 60 samples which were frozen at $-80^{\circ} \mathrm{C}$ until analysis, but not longer than three weeks.

\section{LTLT pasteurization}

Glass vessels containing $20 \mathrm{~mL}$ of human milk each were placed in a water bath with a magnetic stirrer and heated at $62.5^{\circ} \mathrm{C}$ for $30 \mathrm{~min}$. Pasteurized samples were quickly cooled to approximately $20^{\circ} \mathrm{C}$ and immediately analyzed.

\section{High pressure treatment}

Milk samples were subjected to high pressure generated in accordance with the procedure described by Malinowska-Pańczyk et al. [2009]. In the applied method, pressure was generating as a result of the increasing volume during ice for- mation in a sealed vessel filled with water kept at sub-zero temperatures. At a temperature of $-20^{\circ} \mathrm{C}$, the generated pressure equaled $193 \mathrm{MPa}$. Above this temperature, the sample placed in a sealed vessel is affected by the pressure in unfrozen state.

\section{Isolation of fat from human milk}

Fat was isolated from human milk by the modified extraction method described by Röse-Gottlieb in accordance with the Polish Standard [PN-EN ISO 1211:2011]. The procedure of removing solvent residues by drying the isolated fat at $102^{\circ} \mathrm{C}$, recommended by the standard, was replaced with blowing the extracted fat to constant weight under a stream of nitrogen. The above procedure was applied to prevent the oxidation and degradation of FAs under the influence of high temperature, which is particularly important in PUFA analyses.

\section{Preparation of fatty acid methyl esters}

Fatty acids from samples of human milk fat were esterified in accordance with the Polish Standard [PN-EN ISO 12966$-2: 2011]$. The esterification reaction was catalyzed by boron trifluoride $\left(\mathrm{BF}_{3}\right)$. The resulting solutions of fatty acid methyl esters (FAMEs) in hexane were stored at $-20^{\circ} \mathrm{C}$ until analysis.

\section{Analysis of FA composition by high resolution gas chromatography (HR-GC)}

Fatty acid methyl esters were identified based on differences in the length of the carbon chain and the presence, number and configuration of double bonds, using a Hewlett-Packard gas chromatograph with a split-splitless injector and a flame ionization detector (FID) on an Rtx 2330 column (100 m × $0.25 \mathrm{~mm}$ ) (Restek, Bellefonte, PA, USA). The carrier gas was helium with a flow rate of $0.6 \mathrm{~mL} / \mathrm{min}$. Injector and detector temperature was $250^{\circ} \mathrm{C}$. The initial column temperature of $155^{\circ} \mathrm{C}$ was maintained for $30 \mathrm{~min}$, after which it was increased at $1.5^{\circ} \mathrm{C}$ per minute to $210^{\circ} \mathrm{C}$ and held constant until the end of the chromatographic analysis. The analysis was completed within $120 \mathrm{~min}$.

Quantitative and qualitative analyses of fatty acids were performed with the use of FAME reference solutions (Supelco Bellefonte, Pennsylvania, USA; Larodan Fine Chemicals, Malmö, Sweden) and the external standard method using correction factors (according to Polish Standard [PN-EN ISO 5508:1996]). The results for all identified FAs with a chain length of 6 to 24 carbon atoms and up to 6 double bonds were expressed as a weight percentage of total fatty acids.

\section{Determination of the content of secondary products of lipid oxidation}

The oxidation of PUFAs was evaluated by measuring the content of thiobarbituric acid reactive substances (TBARS) in human milk [Turoli et al., 2004]. To this end, $1 \mathrm{~mL}$ of $15 \%$ trichloroacetic acid (TCA), $0.6 \mathrm{~mL}$ of $0.25 \mathrm{~mol} / \mathrm{L} \mathrm{HCl}$ and $0.1 \mathrm{~mL}$ of $0.4 \%$ BHT solution in ethanol were added to centrifuge tubes containing $1 \mathrm{~mL}$ of milk samples. Tube contents were stirred and centrifuged at $6000 \times g$ for $10 \mathrm{~min}$. Then, $0.6 \mathrm{~mL}$ of $0.375 \% \mathrm{TBA}$ was added to the supernatant. The resulting mixture was saturated with 
nitrogen, the tube was capped and heated in a water bath at $95^{\circ} \mathrm{C}$ for $30 \mathrm{~min}$. The samples were rapidly cooled to stop the reaction, distilled water was added to the $4 \mathrm{~mL}$ mark, and the tubes were centrifuged at $6000 \times g$ for $5 \mathrm{~min}$. Supernatant absorbance was measured at $\lambda=534 \mathrm{~nm}$ against the reference. TBARS content was expressed as malondialdehyde (MDA) equivalent content based on a calibration curve showing the correlation between absorbance and MDA concentrations in standard solutions.

\section{Determination of total antioxidant capacity}

The total antioxidant capacity (TAC) of milk was determined with the use of the ABTS reagent [Martysiak-Żurowska \& Wenta 2012]. Centrifuge tubes were filled with $2 \mathrm{~mL}$ of the $\mathrm{ABTS}^{\cdot+}$ solution $(\mathrm{A}=0.700 \pm 0.002$; measured relative to methanol at $\lambda=734 \mathrm{~nm}$ ), and $20 \mu \mathrm{L}$ of milk were added. The mixture was stirred and incubated for $15 \mathrm{~min}$ at room temperature, without light access. After incubation, the mixture was centrifuged at $6000 \times g$ for $5 \mathrm{~min}$, and the absorbance of the colored, clear supernatant was measured immediately at $\lambda=734 \mathrm{~nm}$ relative to methanol. The total antioxidant capacity was measured as Trolox equivalent antioxidant capacity (TEAC) with the use of a calibration curve showing the correlation between absorbance and Trolox concentrations in standard solutions.

\section{Determination of vitamin $\mathbf{C}$ content}

Vitamin $\mathrm{C}$ content of milk was determined by the method described by Romeu-Nadal et al. [2006] which relies on reverse-phase high performance liquid chromatography with UV detection (RP-HPLC/UV). Vitamin C occurs in two forms: ascorbic acid (AsA) and dehydroascorbic acid (DHsA). To determine the total content of vitamin C, DHsA was reduced to AsA with the use of DL-dithiothreitiol (DTT). Degradation of AsA was prevented with the use of a $0.56 \%$ solution of metaphosphoric acid $(\mathrm{V})\left(\mathrm{H}_{3} \mathrm{O}_{3} \mathrm{P}_{9}\right)$ as a stabilizing agent. Then, 15\% TCA was used to obtain clear solutions. Test tubes were filled with $300 \mu \mathrm{L}$ of milk and $800 \mu \mathrm{L}$ of $0.1 \mathrm{~mol} / \mathrm{L}$ DTT. The mixture was shaken for $30 \mathrm{~s}$ and incubated at room temperature for $15 \mathrm{~min}$, without light access. Afterwards, $300 \mu \mathrm{L}$ of $0.56 \% \mathrm{H}_{3} \mathrm{O}_{3} \mathrm{P}_{9}$ and $20 \mu \mathrm{L}$ of TCA were added, and the tubes were repeatedly shaken for $30 \mathrm{~s}$. The mixture was transferred to filtration columns and centrifuged at $4500 \times g$ and $10^{\circ} \mathrm{C}$ for $10 \mathrm{~min}$. The content of AsA was determined without DHsA reduction with DTT.

Vitamin C content of clear solutions was determined by RP-HPLC/UV in the Perkin Elmer liquid chromatography system with a C-18 column (Merck, Darmstadt, Germany) $(125 \times 4.0 \mathrm{~mm}$ I.D., $5 \mu \mathrm{m}$ particle size $)$ and a UV-VIS detector $(\lambda=245 \mathrm{~nm})$. The analyzed solution $(25 \mu \mathrm{L})$ was applied to the column at a temperature of $25^{\circ} \mathrm{C}$. The mobile phase was a mixture of $0.1 \%$ acetic acid and methanol $(95: 5, \mathrm{v}: \mathrm{v})$. Vitamin C content (mg/100 mL), as the combined content of AsA and DHsA, and the AsA content of the analyzed milk samples were calculated with the use of a linear calibration equation expressing the relationship between the surface area of the generated peaks and the AsA content of standard solutions. Vitamin $\mathrm{C}$ recovery of the analytical method was taken into consideration in the final calculations.

\section{Statistical analysis}

The results were expressed as mean values with standard deviation. Data were processed statistically using Statistica 12.0 software. The significance of differences between the content of each analyte in raw human milk (RHM), pasteurized human milk (PHM) and high-pressured human milk (HPHM) was determined by one-way ANOVA and Tukey's post-hoc test. The results were regarded as significant at $\mathrm{p} \leq 0.05$.

\section{RESULTS AND DISCUSSION}

\section{Content and composition of fatty acids}

The presence of more than 50 FAs, including cis- and trans-monoenic isomers of 14:1, 15:1 16:1 and 17:1 FAs, was determined in the analyzed human milk samples. The predominant FAs in human milk fat are: C18:1 (n-9) (36.5\% of total FAs), C16:0 (25\%), C18:2 n-6 (8.7\%), C18:0 (5.7\%), C14:0 $(6.6 \%)$ and $\mathrm{C} 12: 0$ (4.5\%) (Table 1). The above FAs accounted for nearly $90 \%$ of the total fatty acids in human milk lipids. The remaining $10 \%$ was composed of LC-PUFAs such as AA, EPA, DPA and DHA, which are very important for infants, and bioactive CLA. Lipids extracted from the pooled milk sample (from 7 mothers) contained approximately $44 \%$ of saturated fatty acids (SFAs) and $43.5 \%$ of monounsaturated fatty acids (MUFAs). The content of PUFAs in the lipids of the pooled milk sample was estimated at $12 \%$ of the total fatty acids (Table 1).

No significant changes in fatty acid content were noted in milk samples subjected to the pressure of $193 \mathrm{MPa}$ and temperature of $-20^{\circ} \mathrm{C}$. The observed changes in the proportions of FAs (SFA:MUFA:PUFA) in HPHM samples were not statistically significant $(p>0.05)$. The $n-6 / n-3$ PUFA ratio in RHM samples was determined at 7.2:1, and it was not modified by high pressure treatment. In other studies, exposure to pressures as high as $400 \mathrm{MPa}$ at above-zero temperatures $\left(12-26^{\circ} \mathrm{C}\right)$ did not influence the content or composition of FAs in human milk fat either [Moltó-Puigmartí et al., 2011; Delgado et al., 2014]. The content of selected FAs in human milk, including C15:0, C18:3 n-3, C18:3 n-6, C20:0, C20:4 n-6 and C22:6 n-3, was significantly modified under exposure to $600 \mathrm{MPa}$, which led to considerable changes in the proportions of FAs, in particular a substantial drop in the levels of n-3 PUFAs [Delgado et al., 2014]. According to the authors, the significant decrease in PUFA levels under exposure to $600 \mathrm{MPa}$ makes the resulting milk unsuitable for infants and suggests that human milk should not be treated at such high pressures.

The choice of lower pressures for breast milk preservation was also supported by the fact that high-pressure treatment at $600 \mathrm{MPa}$ degraded IgA content by approximately $21 \%$ and the degree of tocopherol degradation was similar to that reported during holder pasteurization. The application of $400 \mathrm{MPa}$ did not induce changes in the content of IgA or $\alpha$ - and $\delta$-tocopherol [Delgado et al., 2014; Permanyer et al., 2010]. Despite the above, treatment at pressures lower than $600 \mathrm{MPa}$, especially at a temperature of $20-35^{\circ} \mathrm{C}$ could be ineffective in eliminating all microbial pathogens from human milk. The treatment's lethal effects on microbial activity can 
TABLE 1. Composition of fatty acids in control samples (RHM) and samples pressurized at $193 \mathrm{MPa}$ at the temperature of $-20^{\circ} \mathrm{C}$ (HPHM) (\% of total FAs \pm SD).

\begin{tabular}{|c|c|c|}
\hline Fatty acids & $\begin{array}{l}\text { RHM } \\
(\mathrm{n}=8)\end{array}$ & $\begin{array}{c}\text { HPHM } \\
(\mathrm{n}=8)\end{array}$ \\
\hline C8:0 & $0.02 \pm 0.032$ & $0.02 \pm 0.022$ \\
\hline $\mathrm{C} 10: 0$ & $0.80 \pm 0.089$ & $0.78 \pm 0.081$ \\
\hline C12:0 & $4.51 \pm 0.415$ & $4.45 \pm 0.057$ \\
\hline $\mathrm{C} 13: 0$ & $0.01 \pm 0.018$ & $0.01 \pm 0.016$ \\
\hline $\mathrm{C} 14: 0$ & $6.63 \pm 0.449$ & $6.70 \pm 0.596$ \\
\hline $\mathrm{C} 14: 19 \mathrm{c}$ & $0.09 \pm 0.054$ & $0.09 \pm 0.069$ \\
\hline Other C14:1 c isomers & $0.07 \pm 0.044$ & $0.07 \pm 0.037$ \\
\hline $\mathrm{C} 15: 0$ & $0.36 \pm 0.051$ & $0.35 \pm 0.050$ \\
\hline $\mathrm{C} 15: 19 \mathrm{c}$ & $0.08 \pm 0.013$ & $0.07 \pm 0.015$ \\
\hline Other C15:1 $(\mathrm{c}+\mathrm{t})$ isomers & $0.06 \pm 0.017$ & $0.06 \pm 0.017$ \\
\hline $\mathrm{C} 16: 0$ & $24.97 \pm 1.309$ & $25.61 \pm 1.233$ \\
\hline Total C16:1 t & $0.65 \pm 0.108$ & $0.58 \pm 0.052$ \\
\hline $\mathrm{C} 16: 19 \mathrm{c}$ & $2.38 \pm 0.386$ & $2.37 \pm 0.384$ \\
\hline Other $\mathrm{C} 16: 1 \mathrm{c}$ isomers & $0.17 \pm 0.051$ & $0.17 \pm 0.053$ \\
\hline $\mathrm{C} 17: 0$ & $0.26 \pm 0.012$ & $0.26 \pm 0.013$ \\
\hline $\mathrm{C} 17: 19 \mathrm{c}$ & $0.04 \pm 0.011$ & $0.04 \pm 0.012$ \\
\hline Other $\mathrm{C} 17: 1$ isomers & $0.22 \pm 0.065$ & $0.13 \pm 0.086$ \\
\hline C18:0 & $5.67 \pm 0.385$ & $5.79 \pm 0.481$ \\
\hline Total C18:1 t & $0.54 \pm 0.024$ & $0.65 \pm 0.036$ \\
\hline C18:1 (n-9) & $36.55 \pm 0.845$ & $36.2 \pm 0.558$ \\
\hline C18:1 (n-7) & $1.82 \pm 0.299$ & $1.84 \pm 0.562$ \\
\hline Other $\mathrm{C} 18: 1 \mathrm{c}$ isomers & $0.21 \pm 0.082$ & $0.17 \pm 0.085$ \\
\hline $\mathrm{C} 18: 2 \mathrm{tt}$ & $0.03 \pm 0.020$ & $0.03 \pm 0.031$ \\
\hline C18:2 (n-6) LA & $8.87 \pm 0.784$ & $8.59 \pm 0.855$ \\
\hline C18:3 (n-6) GLA & $0.03 \pm 0.020$ & $0.03 \pm 0.012$ \\
\hline C18:3 (n-3) ALA & $0.96 \pm 0.057$ & $0.91 \pm 0.067$ \\
\hline C20:0 & $0.14 \pm 0.042$ & $0.13 \pm 0.021$ \\
\hline C20:1 (n-9) & $0.59 \pm 0.041$ & $0.65 \pm 0.062$ \\
\hline Total CLA* & $0.27 \pm 0.051$ & $0.26 \pm 0.014$ \\
\hline C20:2 (n-9) & $0.35 \pm 0.116$ & $0.36 \pm 0.117$ \\
\hline $\mathrm{C} 22: 0$ & $0.04 \pm 0.010$ & $0.03 \pm 0.021$ \\
\hline C20:3 (n-6) DGLA & $0.32 \pm 0.084$ & $0.31 \pm 0.137$ \\
\hline$C 20: 3(n-3)$ & $0.04 \pm 0.012$ & $0.03 \pm 0.013$ \\
\hline C22:1 (n-9) & $0.24 \pm 0.069$ & $0.23 \pm 0.068$ \\
\hline $\mathrm{C} 20: 4(\mathrm{n}-6) \mathrm{AA}$ & $0.52 \pm 0.131$ & $0.51 \pm 0.137$ \\
\hline C20:5 (n-3) EPA & $0.08 \pm 0.040$ & $0.12 \pm 0.069$ \\
\hline $\mathrm{C} 22: 2(\mathrm{n}-9)$ & $0.02 \pm 0.010$ & $0.02 \pm 0.019$ \\
\hline $\mathrm{C} 24: 0$ & $0.05 \pm 0.015$ & $0.05 \pm 0.022$ \\
\hline $\mathrm{C} 24: 1(\mathrm{n}-9)$ & $0.09 \pm 0.025$ & $0.08 \pm 0.031$ \\
\hline $\mathrm{C} 22: 4(\mathrm{n}-6)$ & $0.06 \pm 0.025$ & $0.04 \pm 0.019$ \\
\hline C22:5 (n-3) DPA & $0.10 \pm 0.033$ & $0.10 \pm 0.034$ \\
\hline $\mathrm{C} 22: 5(\mathrm{n}-6)$ & $0.18 \pm 0.088$ & $0.18 \pm 0.094$ \\
\hline C22:6 (n-3) DHA & $0.22 \pm 0.091$ & $0.21 \pm 0.091$ \\
\hline SFA & $43.46 \pm 2.293$ & $44.18 \pm 2.006$ \\
\hline MUFA & $43.80 \pm 0.940$ & $43.41 \pm 0.915$ \\
\hline PUFA & $12.03 \pm 1.690$ & $11.69 \pm 1.695$ \\
\hline PUFA n-3 & $1.39 \pm 0.462$ & $1.36 \pm 0.538$ \\
\hline PUFA n-6 & $9.97 \pm 1.478$ & $9.66 \pm 1.457$ \\
\hline
\end{tabular}

CLA - conjugated linoleic acid. be intensified by applying temperatures higher than $35^{\circ} \mathrm{C}$ or lower than $20^{\circ} \mathrm{C}$ [Pandya et al., 1995; Simpson \& Gilmour, 1997; Reyns et al., 2000].

\section{TBARS content}

TBARS content expressed in terms of MDA is presented in Table 2. The content of TBARS in human milk is determined by various factors, including the mother's health and exposure to cigarette smoke [Ermis et al., 2005]. In the tested samples of raw human milk, TBARS levels were determined at $3.35 \mu \mathrm{mol} / \mathrm{L} \mathrm{MDA}$, and similar results were reported by Turoli et al. [2004]. A minor increase (8.7\%) in TBARS concentrations was noted after LTLT pasteurization, but the observed change was not statistically significant. No changes in TBARS values were noted in the samples subjected to high pressure of $193 \mathrm{MPa}$ at a temperature of $-20^{\circ} \mathrm{C}$. The insignificant rise in TBARS levels and the absence of changes in the content and composition of FAs under the influence of LTLT and high pressure (Table 1) indicate that the above processes do not stimulate the oxidation of LC-PUFAs. Human milk fat occurs in the form of fat globules surrounded by a layer of protein. The protein coat and the abundance of components with antioxidant properties in human milk effectively prevent fat degradation during high-temperature and high-pressure treatment.

\section{Total antioxidant capacity}

The Trolox equivalent antioxidant capacity (TEAC) of raw human milk, milk processed by LTLT pasteurization and milk subjected high pressure at sub-zero temperature is presented in Table 2. The TEAC value of RHM samples was estimated at $40 \mathrm{mg} \mathrm{TE} / 100 \mathrm{~mL}$. The results of the analysis indicate that high-pressure treatment at sub-zero temperature did not affect the antioxidant properties of human milk (Table 2). LTLT pasteurization induced a minor and statistically insignificant drop in TEAC values (by approx. 7\%). Silvestre et al. [2008] measured the antioxidant capacity of human milk with the use of commercially available assay kits (PAO-DELTACLON, KPA-050 Cosmo Bio Co. Ltd.) and demonstrated a significant decrease in its values (by $66 \%$ on average) in milk heated at $63^{\circ} \mathrm{C}$ for $30 \mathrm{~min}$. The assay measures the amount of the colored complex produced by the Chromatic Solution substrate (Bathocuproine) and $\mathrm{Cu}$ (I) ions reduced from $\mathrm{Cu}$ (II) by antioxidant substances in the sample. The differences in the results reported by Silvestre et al. [2008] and our findings could be attributed to different methods applied to determine the antioxidant properties of milk. The two analytical methods would have to be compared for the above assumption to be validated. According to Silvestre et al. [2008], their method supports the identification of both hydrophilic (vitamin C and glutathione) and hydrophobic antioxidants (vitamin E), but Prior et al. [2005] demonstrated that the method where $\mathrm{Cu}$ (II) ions are reduced to $\mathrm{Cu}$ (I) has certain limitations in determining the content of lipophilic substances with antioxidant properties (such as $\beta$-carotene). In our study, the ABTS reagent was used to determine the Trolox-equivalent antioxidant capacity of human milk which expresses the activity and content of all antioxidants in a given sample, including vitamins, enzymatic systems that scavenge free radicals, un- 
TABLE 2. Thiobarbituric acid reactive substances (TBARS, $\mu \mathrm{mol}$ $\mathrm{MDA} / \mathrm{L})$, total antioxidant capacity $(\mathrm{mg} \mathrm{TE} / 100 \mathrm{~mL})$, vitamin C and AsA $(\mathrm{mg} / \mathrm{L})$ concentrations in raw (RHM), LTLT pasteurized (PHM) and pressurized (HPHM) human milk.

\begin{tabular}{l|c|c|c}
\hline & $\begin{array}{c}\text { RHM } \\
(\mathrm{n}=20)\end{array}$ & $\begin{array}{c}\text { PHM } \\
(\mathrm{n}=20)\end{array}$ & $\begin{array}{c}\text { HPHM } \\
(\mathrm{n}=20)\end{array}$ \\
\hline TBARS & $3.35 \pm 0.64$ & $3.64 \pm 0.70$ & $3.25 \pm 0.68$ \\
TEAC & $40.48 \pm 5.44$ & $37.53 \pm 4.52$ & $41.36 \pm 4.56$ \\
Vitamin C & $34.37 \pm 4.56^{\mathrm{a}}$ & $22.23 \pm 4.59^{\mathrm{a}, \mathrm{b}}$ & $32.29 \pm 4.82^{\mathrm{b}}$ \\
AsA & $17.41 \pm 2.50^{\mathrm{a}}$ & $13.27 \pm 2.53^{\mathrm{a}}$ & $15.46 \pm 2.59^{\mathrm{a}}$ \\
\hline
\end{tabular}

The same letters in the same row indicate statistically significant differences (Tukey's test, $\mathrm{p}<0.05$ ).

known antioxidants, as well as the interactions between those components [Prior et al., 2005; Turoli et al., 2004].

\section{Vitamin $C$ and AsA content}

Human milk is abundant in vitamin $\mathrm{C}$, a powerful antioxidant. Vitamin $\mathrm{C}$ is sensitive to external factors such as temperature, light and $\mathrm{pH}$, therefore, it is an effective indicator of changes induced by processing in food products, including human milk.

The content of total vitamin $\mathrm{C}$, expressed as the combined content of AsA and DHsA, and the content AsA were determined in samples of raw human milk, milk treated by LTLT pasteurization and milk subjected to high pressure treatment (Table 2). The total vitamin C concentration in RHM samples was estimated at $34.4 \mathrm{mg}$ per L of milk (Table 2). Pasteurization significantly reduced the content of vitamin $\mathrm{C}$ and AsA by $35 \%$ and $24 \%$, respectively. Similar results were reported by Van Zoeren-Grobben et al. [1987] in whose study, LTLT pasteurization decreased vitamin $\mathrm{C}$ content of human milk by approximately $36 \%$. In another study, vitamin $\mathrm{C}$ levels were reduced by around $20 \%$ and AsA concentrations decreased by around $16 \%$ when milk samples were heated at $62.5^{\circ} \mathrm{C}$ for 30 min [Moltó-Puigmarti et al., 2011].

A minor and statistically insignificant (approx. 6\%) decrease in vitamin $\mathrm{C}$ levels was observed in milk subjected to high pressure of $193 \mathrm{MPa}$ at a temperature of $-20^{\circ} \mathrm{C}$ (Table 2). The above treatment led to a significant drop of more than $11 \%$ in AsA concentrations. The noted results suggest that AsA is a less stable form of vitamin $\mathrm{C}$ in human milk than DHsA. There are no published studies analyzing the influence of high pressure on the content of vitamin $\mathrm{C}$ and AsA in human milk under conditions similar to those applied in this experiment. Moltó-Puigmarti et al. [2011] did not report any changes in AsA levels and observed only a minor 4\% drop in vitamin $\mathrm{C}$ concentrations in human milk subjected to pressures as high as $600 \mathrm{MPa}$ at above-zero temperature.

In our study, the significant decrease in vitamin $\mathrm{C}$ and AsA content of milk processed by LTLT pasteurization, the drop in AsA concentrations in milk samples subjected to high pressure treatment and non-significant changes in TEAC values indicate that bioactive components of human milk other than vitamin $\mathrm{C}$ are characterized by a higher antioxidant activity and greater resistance to external stressors than vitamin $\mathrm{C}$.

\section{CONCLUSIONS}

Our findings indicate that the content and composition of FAs, including LC-PUFAs, are not modified under exposure to high pressure at sub-zero temperature. LTLT pasteurization and the application of high pressure of $193 \mathrm{MPa}$ at $-20^{\circ} \mathrm{C}$ do not induce the formation of secondary oxidation products of LC-PUFAs, despite naturally high levels of those FAs in human milk.

LTLT pasteurization leads to a significant drop in the vitamin $\mathrm{C}$ content of human milk, whereas high pressure treatment at $193 \mathrm{MPa}$ and $-20^{\circ} \mathrm{C}$ does not exert a significant influence on vitamin $\mathrm{C}$ levels. Both treatments significantly reduce the AsA content of human milk, but the effect of pressurization is weaker. LTLT pasteurization causes a minor and statistically insignificant decrease in TEAC values, whereas milk samples subjected to high pressure retain their antioxidant properties. The influence of high pressure treatment on AsA levels and the absence of significant changes in TEAC values point to the relative stability of the remaining antioxidant components in human milk. Further research is needed to determine the effect of high pressure of approximately $200 \mathrm{MPa}$ and sub-zero temperatures on other, mainly thermolabile, components of human milk, which are degraded by LTLT pasteurization.

\section{ACKNOWLEDGEMENTS}

The authors would like to thank the mothers for their time and effort in providing milk samples.

\section{RESEARCH FUNDING}

The project was funded by a grant from the National Science Centre, allocated pursuant to decision No. DEC-2013/09 / B / NZ9 / 01779.

\section{CONFLICT OF INTEREST}

Authors declare no conflict of interest.

\section{REFERENCES}

1. Canfield L.M., Clandinin M.T., Davies D.P., Multinational study of major breast milk carotenoids of healthy mothers. Eur. J. Nutr., 2003, 42, 133-141.

2. Delgado F.J., Cava R., Delgado J., Ramirez R., Tocopherols, fatty acids and cytokines content of holder pasteurized and highpressure processed human milk. Dairy Sci. Technol., 2014, 94, 145-156.

3. Emmett P.M., Rogers I.S., Properties of human milk and their relationship with maternal nutrition. Early Hum. Dev., 1997, 49, S7-S28.

4. Ermis B., Yildirim A., Örs R., Tastekin A., Ozkan B., Influence of smoking on serum and milk malondialdehyde, superoxide dismutase, glutathione peroxidase, and antioxidant potential levels in mothers at the postpartum seventh day. Biol. Trace Elem. Res., 2005, 105, 27-36. 
5. Esterbauer H., Schaur R.J., Zollner H., Chemistry and biochemistry of 4-hydroxynonenal, malonaldehyde and related aldehydes. Free Rad. Biol. Med., 1991, 11, 81-128.

6. Friel J.K., Friesen R.W., Harding S.V., Roberts L.J., Evidence of oxidative stress in full term healthy infants. Pediatr. Res., 2004 , $56,878-882$.

7. Hayakawa K., Ueno Y., Kawamura S., Kato T., Hayashi R., Microorganism inactivation using high pressure generation in sealed vessels under sub-zero temperature. Appl. Microbiol. Biotechnol., 1998, 50, 415-418.

8. Innis S.M., King D.J., Trans fatty acids in human milk are inversely associated with concentration of essential all-cis n-6 and n-3 fatty acids and determine trans, but not n- 6 and n-3, fatty acids in plasma lipids and breast-fed infants. Am. J. Clin. Nutr., 1999, 70, 383-390.

9. Januszewicz P., Stolarczyk A., Socha P., Socha J., Co należy uwzględnić w Polskim Konsensusie Tłuszczowym w odniesieniu do żywienia niemowląt i dzieci? Pediatr. Współcz. Gastroenterol. Hepatol. Żywienie Dziecka, 1999, 1,2/3, 133-138 (in Polish).

10. Kent J.C., Mitoulas L.R., Cregan M.D., Ramsay D.T., Doherty D.A., Hartmann P.E., Volume and frequency of breastfeedings and fat content of breast milk throughout the day. Pediatrics, 2006, 117, 3, E340-E387.

11. Malinowska-Pańczyk E., Kolodziejska I., Murawska D., Wolosewicz G., The combined effect of moderate pressure and chitosan on Escherichia coli and Staphylococcus aureus cells suspended in a buffer and on natural microflora of apple juice and minced pork. Food Technol. Biotechnol., 2009, 47, 202-209.

12. Martysiak-Żurowska D., Wenta W., A comparison of ABTS and DPPH methods for assessing the total antioxidant capacity of human milk. Acta Sci. Pol. Technol. Alim., 2012, 11, 83-89.

13. Mazri C., Sanchez L., Ramos S.J., Calvo M., Pérez M.D., Effect of high-pressure treatment on denaturation of bovine lactoferrin and lactoperoxidase. J. Dairy Sci., 2012, 95, 549-557.

14. Moltó-Puigmarti C., Permanyer M., Castellote A.I., López-Sabater M.C., Effects of pasteurization and high-pressure processing on vitamin $\mathrm{C}$, tocopherols and fatty acids in mature human milk. Food Chem., 2011, 124, 697-702.

15. Pandya Y., Jewett F., Hoover D.G., Concurrent effects of high hydrostatic pressure, acidity and heat on the destruction and injury of yeasts. J. Food Prot., 1995, 58, 301-304.

16. Permanyer M., Castellote C., Ramirez-Santana C., Audi C., Perez-Cano F.J., Castell M., Lopez-Sabater M.C., Franch A., Maintenance of breastmilk immunoglobulin A after high pressure processing. J. Dairy Sci., 2010, 93, 877-883.

17. Prior R.L., Wu X., Schaich K., Standardized methods for the determination of antioxidant capacity and phenolics in foods and dietary supplements. J Agric. Food Chem., 2005, 53, 4290-4302.
18. PN-EN ISO 1211:2011. Milk - Determination Of Fat Content Gravimetric Method (Reference Method).

19. PN-EN ISO 12966-2:2011. Animal and vegetable fats and oils Gas chromatography of fatty acid methyl esters - Part 2: Preparation of methyl esters of fatty acids (ISO 12966-2:2011).

20. PN-EN ISO 5508:1996. Animal And Vegetable Fats And Oils - Analysis By Gas Chromatography Of Methyl Esters Of Fatty Acids.

21. Reyns K.M.F.A., Sootjens C.C.F., Cornelis K., Weemaes C.A., Hendrickx E., Michiels Ch.W., Kinetic analysis and modeling of combined high-pressure-temperature inactivation of the yeast Zygosaccharomyces bailii. Int. J. Food Microbiol., 2000, 56, 199-210 .

22. Romeu-Nadal M., Castellote A.I., Lopez-Sabater M.C., Effect of cold storage on vitamins $\mathrm{C}$ and $\mathrm{E}$ and fatty acids in human milk. Food Chem., 2008, 106, 65-70.

23. Siegel B.V., Vitamin C and immune response in health and disease. 1993, in: Nutrition and Immunology (ed. D.M. Khuzfled). Plenum Press, New York, pp. 167-196.

24. Silvestre D., Miranda M., Muriach M., Almansa I., Jereno E., Romero F.J., Antioxidant capacity of human milk: effect of thermal conditions for the pasteurization. Acta Paediatr., 2008, 97, 1070-1074.

25. Simpson R.K., Gilmour A., The resistance of Listeria monocytogenes to high hydrostatic pressure in foods. Food Microbiol., 1997, 14, 567-573.

26. Stolarczyk A., Socha P., Tłuszcze w żywieniu niemowląt. Nowa Pediatria, 2002, 3, 200-203 (in Polish).

27. Tewari G, Jayas D.S., Holley R.A., High pressure processing of foods: an overview. Sci. Aliments., 1999, 19, 619-661.

28. Tully D.B., Jones F., Tully M.R., Donor Milk: What's in It and What's Not. J. Hum. Lact., 2001, 17, 152-155.

29. Turoli D., Testolin G., Zanini R., Bellu R., Determination of oxidative status in breast and formula milk. Acta Paediatr., 2004, 93, 1569-1574.

30. Van Gysel M., Cossey V., Fieuws S., Schuermans A., Impact of pasteurization on the antibacterial of human milk. Eur. J. Pediatr., 2012, 171, 1231-1237.

31. Van Zoeren-Grobben D., Schrijver J., Van den Berg H., Berger H.M., Human milk vitamin content after pasteurization, storage or tube feeding. Arch. Dis. Child., 1987, 62, 161-165.

32. Viazis S., Farkas B.E., Allen J.C., Effects of high pressure processing on immunoglobulin A and lysozyme activity in human milk. J. Hum. Lact., 2007, 23, 253-261.

Submitted: 30 July 2015. Revised: 3 April 2016. Accepted: 20 April 2016. Published on-line: 5 September 2016. 